\title{
Questioning and reading goals: Information-seeking questions asked on scientific texts read under different task conditions
}

Koto Ishiwa1, Vicente Sanjose'2 and Jose' Otero1* 1Departamento de Fı'sica, Universidad de Alcala', Alcala' de Henares, Madrid, Spain 2Universidad de Valencia, ERI-Polibienestar y Dida'ctica de las Ciencias Experimentales, Universitat de Valencia, Valencia, SpainAuthors:

\author{
Abstract \\ Background: \\ A number of studies report that few questions are asked in classrooms and that \\ many of them are shallow questions. \\ Aims: \\ This study investigates the way in which reading goals determine questioning on \\ scientific texts. Reading goals were manipulated through two different tasks: reading for \\ understanding versus reading to solve a problem. \\ Sample: \\ A total of 183 university students. \\ Methods: \\ In the first and third questioning experiments the participants read two short \\ texts. Students in one condition were instructed to understand the texts, while in the \\ alternative condition they had to read texts to solve a problem. Students were instructed \\ to write down any questions they might have about the texts. The questions were \\ categorized according to the type of underlying obstacle: associative, explanatory or \\ predictive.
}

The second experiment used a think-aloud methodology to identify the mental representations generated by the students. 
Results and Conclusions:

The two questioning experiments show that the questions asked depend on the reading goals. Significantly more explanation questions were asked in the understanding condition than in the problem-solving condition. Also, the two conditions were found to have a different influence on the generation of association and explanation questions. Very few prediction questions were asked in either condition. The think-aloud experiment revealed that the mental representations attempted by readers under the two conditions were indeed different. In conclusion, the experiments showed that, given a certain textual input, readers’ questions depend on the reading goals associated with tasks. 


\section{Introduction}

Although questioning is a powerful metacognitive tool (Gaveleck \& Raphael, 1985; King, 1989; Wong, 1985) a number of studies report that few questions are asked in classrooms (Dillon, 1988; Graesser \& Person, 1994; van der Meij, 1988). Additionally, many of these questions, including those asked by teachers, are shallow questions (Dillon, 1990; Graesser \& Person, 1994). This study explores the relation between the quantity and type of questions asked on texts, and readers' goals. We examine how good questioning is dependent on appropriate reading goals, i.e., attempted mental representations of discourse suitable for the task at hand.

The production of a question is a complex process involving several stages: anomaly detection, question articulation, and social editing (Graesser \& McMahen, 1993). We focus on the first stage, specifically on the relation between reading goals and the identification of question-triggering anomalies. To analyze this relation, short scientific texts were read by university students under different task conditions involving different reading goals. We examined the number and type of questions asked under each task condition. Different reading tasks should correspond to different representations of discourse in memory. Questions are conceived as attempts to overcome the obstacles found when trying to build these representations (Otero, 2009). In the following sections we analyze how the attempt to build these different representations is expected to lead to the detection of different obstacles and to the asking of different questions.

\section{Mental representations of discourse, reading goals and questions}

There are several text comprehension models that postulate different levels of representation of discourse in memory (Graesser, Millis, \& Zwaan, 1997; Kintsch, 1998; Van Dijk \& Kintsch, 1983). These include at least surface structure, textbase, and 
situation model. The surface structure is a representation of discourse that preserves the text's exact wording and syntax. Singing songs, for example, involves memorizing the surface structure of the lyrics. However, the surface structure of texts read under most conditions in schools is quickly forgotten, while the meaning is preserved (Kintsch, Welsch, Schmalhofer, \& Zimny, 1990). The representation of meaning corresponds to the second level of representation: the textbase. The textbase captures the meaning of the explicit text in the form of an interrelated set of propositions (Kintsch, 1988, 1998). Lastly, the situation model, or mental model, is the referential content of what the text is about (Johnson-Laird, 1983; Van Dijk \& Kintsch, 1983). It is a representation of the situation described by a text, and involves knowledge possessed by readers that may be incorporated into this level to a variable extent. For instance, the mental representation of a novel's content normally includes a substantial amount of reader knowledge associated with the representation of the explicit text meaning that constitutes the textbase.

Otero and Graesser (2001) focus on the role of discourse representations in explaining questions that a reader may ask about a text. These questions are conceptualized as instruments to build an appropriate mental representation of discourse (Otero, 2009). What counts as an appropriate mental representation for a particular reader varies with the reading goal. A basic assumption of constructionist theories of discourse comprehension, such as Graesser, Singer, and Trabasso’s (1994), concerns the purposeful character of reading. Accordingly, several studies have shown that, given the same textual input, different reading goals lead to different mental representations (Coleman, Brown, \& Rivkin, 1997; Geiger \& Millis, 2004; Schmalhofer \& Glavanov, 1986), in particular different inferences generated (Graesser \& Kreuz, 1993; Lorch, Lorch, \& Klusewitz, 1993; Narvaez, van den Broek, \& Barrón-Ruiz, 1999) or different 
emphasis on the textbase vs. the situation model representation. For instance, Van den Broek, Lorch, Linderholm, \& Gustafson (2001) found that readers with a study goal drew more explanatory and predictive inferences from the same text than readers with an entertainment goal. Mills, Diehl, Birkmire, and Mou (1995) examined the effect of reading a procedural text for recall versus reading it to perform the action described by the text. As predicted, readers in the first condition recalled the text better while readers in the second condition performed the task better. The authors conclude that "read-todo" subjects focus on the construction of a situation model, whereas "read-to-recall” subjects were found to aim at a representation of the textbase

Therefore, given a particular text, different reading goals are expected to lead to different mental representations and therefore different potential difficulties for a reader. Given certain conditions, these difficulties may become question-triggering obstacles (Otero, 2002). Anomalies such as gaps, inconsistencies or contradictions have been traditionally conceived to be at the root of questioning (Graesser, Bagget, \& Williams, 1996; Graesser, Lu, Olde, Cooper-Pye, \& Whitten, 2005; Graesser, Pearson, \& Huber, 1992; Person, Graesser, Magliano, \& Kreuz, 1994). We intend to show that anomalies such as these do not have an invariant character as question-triggering obstacles, but rather a relative status depending on the reading goal.

\section{Types of obstacles and questions}

Oakhill (1993) studied children’s reading problems and categorized them into three basic types of difficulties: at the single-word level, at the sentence level, and in drawing inferences from text, integrating ideas and monitoring comprehension. Our more restricted aim consists of identifying the classes of obstacles encountered by a relatively competent reader who asks questions on a relatively simple scientific text. We assume that, given the students' level and the characteristics of the texts, readers are 
able to build a representation of discourse at the surface and textbase levels. Therefore, we examined the difficulties involved in building a situation model representation. These basically correspond to Oakhill's (1993) higher-order difficulties in drawing inferences or integrating ideas, because the construction of a situation model involves generating inferences that elaborate the textbase.

Extensive research has been conducted on the inferences that are generated when building situation models of texts, especially of the narrative genre (see, for instance, Graesser \& Zwaan, 1995). Many taxonomies of inferences have been proposed in the literature, depending on criteria such as the amount of cognitive resources involved, direction, information source, content, etc (León \& Pérez, 2003). In a situation of conscious understanding such as ours, Trabasso \& Magliano (1996) identified three broad classes of inferences that may occur: associative, explanatory, and predictive. Associations provide information about features, properties, relations and, in general, descriptive detail of the entities mentioned in a text. Explanations provide reasons as to why something occurs. Lastly, predictions are forward oriented and include consequences of events, and anticipate occurrences.

We take these three classes of inferences as the basis to distinguish the three types of possible obstacles encountered and questions asked when a reader attempts to build a situation model: questions linked to associations, to explanations, and to predictions. First, readers may find obstacles to representing the objects and processes described or explained in a text. For example, imagine a student trying to understand a passage describing sailing. She may attempt to draw association inferences in order to suitably represent a "lugsail" mentioned in the passage. However, she may be unable to do so and may address the obstacle by asking: What is a lugsail? Association questions address the need to adequately represent the entities of the system under consideration, 
as well as their properties, and are frequently formulated as who, what, how, when and where questions.

There are several possible reasons for finding an association obstacle and asking an association question. The simplest one may be an unknown word meaning preventing the reader from building a textbase. But obstacles to the representation of entities may also exist when meanings are known, but there are difficulties in accessing referents. For example, readers may know the meaning of “mast” but they may be unable to identify a referent to this term in a particular description of a sailing vessel: What mast is it? In addition, representing entities is not an all-or-nothing matter, since it can be achieved to varying degrees. An obstacle can be found when objects and processes are identified but not enough features of the objects or processes are known. For instance, a reader of the text mentioned above on sailing may find an obstacle to appropriately representing features of the specific sail mentioned, and may therefore ask What is the shape of a lugsail?

The second kind of obstacles is associated with the attempt to draw explanatory inferences and the impossibility to do so. Explanation questions concern justifications for or explanations about the entities included in a situation model, i.e., why objects and processes are the way they are. Causal relations are important to readers of both narrative (Keenan, Baillet, \& Brown, 1984; Trabasso \& Sperry, 1985) and expository texts (Coté, Goldman, \& Saul, 1998) and constitute likely obstacles for readers. Explanation questions, linked to explanation obstacles, frequently expressed as Why?, are the second type of questions associated with the construction of a situation model. Lastly, there are prediction obstacles that relate to difficulties in generating predictive inferences, i.e., obstacles to foreseeing consequences. They correspond to 
what happens next or what if questions, such as What happens when a keel breaks while sailing?

\section{Hypotheses of the study}

The basic hypothesis examined in this study is that, given a particular text and readers with certain knowledge, goals determine the obstacles encountered and the questions that may be asked to overcome such obstacles. We manipulated reading goals and the mental representation attempted by readers through two different tasks: reading a scientific text for understanding versus reading it to solve an algorithmic problem directly associated with it.

Although understanding and comprehension are admittedly fuzzy terms (Weaver, 1990), they have sometimes been explicitly defined as building an adequate situation model of discourse (Graesser, Singer \& Trabasso, 1994; Glenberg, Kruley, \& Langston, 1994; Kintsch, 1998). As pointed out, this involves generating inferences to achieve situation models of variable articulation and detail. In a situation of conscious understanding of scientific texts describing natural phenomena we anticipated a key role for explanatory inferences. This should be expected, in the first place, because conscious understanding, as regarded by constructionist theories, is explanation based (Graesser et al., 1994). The importance of causal or goal-based explanations has been amply demonstrated by research on the understanding of narratives (Klin, 1995; Suh \& Trabasso, 1993; Trabasso \& Suh, 1993; Van den Broek, 1990), but the less abundant research on expository texts also points toward the importance of explanatory inferences. Millis \& Graesser (1994), Singer \& Gagnon (1999), and Wiley \& Myers (2003) found evidence for causal antecedent inferences, a basic explanatory process, when undergraduate students read scientific texts. Coté, Goldman, \& Saul (1998) found that the use of self-explanations was the dominant type of reasoning in think-aloud 
protocols of $4^{\text {th }}$ and $6^{\text {th }}$ grade students reading informational text. Lastly, indirect evidence of the importance of explanations in expository texts is provided by the finding of a positive relationship between logical relatedness and recall of statements in expository texts (Varnhagen, 1991). Logical relations include the abstract explanatory relations that operate in expository texts, in addition to the physically or psychologically causative conditions considered in research on narratives.

Therefore, in correspondence with the importance of explanatory inferences in scientific text understanding, a high incidence of explanation obstacles would be expected in the case of students reading for understanding scientific texts that describe and explain natural phenomena. Direct support for the abundance of explanation obstacles may be found in a study by Costa, Caldeira, Gallástegui, and Otero (2000). Indeed, secondary school students where asked to read science passages similar to the ones used in our study. The students were instructed to ask questions that might help them understand the passages, and the questions were categorized according to the 18item taxonomy of Graesser, Person, \& Huber (1992). The classification showed an overwhelming majority of questions in the "causal antecedent" category of the taxonomy.

Quite a different mental representation and different obstacles would be expected in a condition consisting in reading to solve an algorithmic problem. Based on the target passage, we built a simple problem that could be immediately solved by the application of a well-known problem schema. In a situation of routine problem-solving such as this, the problem schema guides not only the search process in the problem space, but also the process of understanding the problem statement: the expectations of the problem schema lead the solver to read the problem statement selectively (Van Lehn, 1989), emphasizing the elements that may fill the schema's slots as suggested by 
the experiments conducted by Baruk (1985). In these studies, seven- and nine-year-old children were given arithmetic problem statements such as: In a ship there are 25 goats and 18 lambs. How old is the captain? About $75 \%$ of the students performed calculations to find a solution, unaware that the data were irrelevant. This phenomenon, replicated with different statements and samples, indicates that the students use the figures provided (25 and 18 in this case) as appropriate information to fill the slots of a readily available addition schema. Since it provides an apparently sensible solution, no attempt is made to create an appropriate representation of the situation described by the problem statement.

Therefore, we did not expect all the elements in our problem statements to be equally elaborated: there would be differences depending on their relevance as defined by the problem schema. In particular, causal relations that do not play a role in the problem schema may be minimally elaborated. Moreover, standard physics problems may be solved with a limited understanding of causal, explanatory relations, as shown by Hung and Jonassen (2006).

Based on the above expectations, we carried out three experiments. The first one was a basic experiment to test the prediction of a greater number of explanation obstacles and explanation questions in the understanding condition than in the problemsolving condition. To do this, a group of beginner university students read short passages under these two task conditions with instructions to ask questions if necessary. The questions asked were categorized according to the taxonomy presented above. The second experiment was intended to ascertain the hypothesized differences in the mental representations attempted under the two task conditions, and to substantiate the underlying question-generation mechanism. To examine the expected difference in the situation models, students were asked to read the experimental passages using a think- 
aloud procedure to record their inferencing activity. This provided a window to the mental representation attempted by readers in each of the two task conditions. Lastly, Experiment 3 replicated the first experiment with a sample of students taken from the same pool as those participating in Experiment 2.

\section{Experiment 1}

Two science passages were read to prepare for a comprehension test (understanding condition) or, alternatively, to solve a problem (problem-solving condition). The participants had instructions to ask the questions they considered necessary to carry out the task. Explanation questions were expected to be more frequent in the understanding condition. In particular, we expected more explanation questions on certain particular information specifically selected to be at variance with common sense beliefs.

We did not have clear predictions regarding association questions in the two conditions. However, to check for the effect of task condition on the detection of obstacles to representing entities, a term unknown to the readers was introduced in one of the versions of the experimental materials. We aimed to check whether this unknown term would constitute an objective obstacle (of the association type) independent of task condition, or, alternatively, whether the perception of the obstacle would depend on the task and the reading goal. Lastly, since predictive inferences are rarely drawn when reading scientific texts such as those used in this study (Millis \& Graesser, 1994), we expected few prediction questions in either condition.

\section{Method}




\section{Subjects}

Sixty-eight first-year Biology students at the University of Alcalá (Madrid) (around 19 years old) participated in Experiment 1. Thirty-four subjects were randomly assigned to each of the task conditions. The experimental tasks were presented as part of the activities in an introductory physics course taught by one of the authors. The students were given credits.

\section{Materials}

Two experimental passages were used: Sailing and Defrosting (see Appendix for the Sailing example). These experimental passages described physical situations that involved relatively surprising phenomena: Sailing against the wind, and thawing on "cold" surfaces. The passages were the same in both experimental conditions, except for the inclusion of a sentence requesting a calculation in the problem-solving condition. The first two sentences introduced a certain physical setting. The third sentence, starting with “However...”, presented a discrepant event, i.e., a phenomenon at variance with common sense beliefs, which might normally require an explanation. However, the information was irrelevant to solving the problem in the problem-solving condition.

An unknown term (shown in italics in the Appendix) was introduced in one version of the passages (the “difficult version”). This was done to specifically check for the effect of goals on association questions aimed at identifying this unknown entity. Each student read one passage in the regular version and the other in the difficult version.

Three-page booklets were handed out to the participants. Each passage was included in a different page, with ample space in the page to write down questions. The order of presentation of the passages was counterbalanced, and the first page of the booklet always included the task instructions. 
In the understanding condition the instructions requested the participants to read the two passages in order to understand them and to be ready to take a multiple choice test about their content in the following session. The test was announced to have similar characteristics to others already taken in the course. These were inspired by well-known physics comprehension tests such as the "Force Concept Inventory” (Hestenes, Wells, \& Swackhamer, 1992) or the "Determining and Interpreting Resistive Electric Circuits Concepts Test” (Engelhardt \& Beichner, 2004). In the problem-solving condition, the instructions requested the participants to read the two passages in order to solve the problems in the following session. All of the students had substantial experience in solving standard physics problems such as those included in the course textbook (Kane \& Sterheim, 1980/1992).

\section{Procedure}

The students were given the booklets during a regular physics class session. Both experimental tasks were presented as part of coursework. In both conditions, students were asked to carefully read the instructions and the passages at their own pace. At the end the subjects were debriefed, informing them that there would not be a second session. The entire procedure took about 30 minutes.

\section{Measurements}

The questions asked were classified as association questions, explanation questions, and prediction questions, according to the categorization explained above. What is the mass of the ship? or What is the defrosting time? are examples of the association questions asked. Why does a suitable wind for sailing have a speed of $30 \mathrm{~km} / \mathrm{h}$ ? or Why does this phenomenon occur? are examples of explanation questions. If it is placed on wood, will it defrost in the same way? or Is sailing possible when the wind is weak? are examples of prediction questions. 
All of the questions were classifiable into one of the three categories, corroborating the sufficiency of the framework (Ishiwa, Macías, Maturano, and Otero 2011). In addition to the general categorization of questions, two specific measurements were made. First, What is? questions on the unknown term were counted. Second, explanation questions specifically relating to the discrepant event, such as Why does the frozen steak on marble thaw out before the one on wood? were also counted.

Problem-solving generally involves a search through problem space, starting from an initial state that is the product of understanding the problem statement (Newell \& Simon, 1972). Given the characteristics of the problems used in this experiment, this search involved minimal obstacles. However, to consider equal target content, only questions relating to the initial state were considered in the problem-solving condition. Four questions related to the search through problem space, such as Can it be done using a rule of three? were discarded. This amounted to $2.1 \%$ of the total number of questions asked.

Two of the authors categorized a subset of 50 questions resulting in a Kappa coefficient of intercoder agreement of .92. Questions specifically relating to the target sentence describing the discrepant event were also counted.

\section{Results}

The reading task, i.e., understanding or problem-solving, was a between-subjects variable, while lexical difficulty based on the unknown term was a within-subjects variable. As the assumptions on normality and homogeneity of variance for the number of questions asked were not upheld, nonparametric tests were used: the Mann-Whitney U test for comparisons across task conditions, and the Wilcoxon matched-pairs signedranks test for comparisons across lexical difficulty conditions. 
Table 1 shows average numbers of questions asked under the experimental conditions . Firstly, the effect of task condition on association questions was examined by means of two measurements: (1) association questions asked on the regular version of the passages only, and (2) questions specifically relating to the unknown term in the difficult passages. None of the measurements resulted in significant differences between conditions: the difference in association questions asked on the regular passages was non-significant $(U=530.0, p=.543)$ as well as the difference in specific questions relating to the unknown term $\left(M_{U N D}=.47, S D_{U N D}=.51 ; M_{P R O B S O L V}=.29, S D_{P R O B S O L V}\right.$ $=.46 ; U=476.0, p=.145)$.

Secondly, regarding explanation questions, Wilcoxon matched-pairs signedranks tests revealed no significant differences between explanation questions asked on regular passages and difficult passages, both in the understanding condition $(Z=$ $-0.042, p=0.961)$, and in the problem-solving condition $(Z=-1.19, p=.234)$. Therefore, explanation questions were counted collapsing across difficulty conditions. As hypothesized, significantly more explanation questions per subject and per passage were asked in the understanding condition than in the problem-solving condition ( $U=$ 251.5, $p<.001$ ), with a large effect size , $d=1$.16. Regarding questions on the discrepant event, significant differences were also found between the understanding condition $\left(\mathrm{M}_{\mathrm{UND}}=.59, \mathrm{SD}_{\mathrm{UND}}=.56\right.$ and the problem-solving condition $\left(\mathrm{M}_{\mathrm{PROBSOLV}}=\right.$ $\left..15, \mathrm{SD}_{\mathrm{PROBSOLV}}=.34 ; U=303.0, p<.001\right)$.

Thirdly, there was a small number of prediction questions, and no significant differences between the average number of this kind of questions (collapsing across difficulty conditions as was done for explanation questions) in the understanding condition and the problem-solving condition $(U=557.5, p=.802)$. 


\section{Discussion}

The results support our hypothesis regarding explanation questions. Given the same input, the importance of explanation questions is different depending on the reading goal. This result is found both for explanation questions in general and specifically for questions on the discrepant event.

Very few prediction questions were asked, as expected. Asking prediction questions on this kind of texts is found to be rather infrequent, in both the understanding and the problem-solving tasks.

The task conditions seem to affect association and explanation questions in a different way. Obstacles regarding knowledge of entities, and the questions asked on them were not significantly different between task conditions in contrast to the difference in explanation questions. Also, questions on the unknown term were not significantly different between task conditions. This suggests a status for the representation of entities that is different from the representation of explanations. The need to know about entities and their characteristics, as shown by the questions asked, did not vary significantly between task conditions. Therefore it seems to be a more stable requirement than the need to include explanations, which changed significantly between conditions.

In sum, goals corresponding to different task conditions and explanation questions were shown to be related as expected. However, evidence of differences in the mental representations attempted under the two conditions would be necessary to support the plausibility of the underlying hypothesized mechanism: do students in the understanding condition attempt to build situation models including more explanations than in the problem-solving condition? To examine this expected difference, a new group of students was asked to read the experimental passages using a think-aloud 
procedure to record their inferencing activity, the crucial variable immediately determining the questions asked.

\section{Experiment 2}

Think-aloud procedures have been used in many studies to reveal inferences generated while reading texts (Collins Brown \& Larkin, 1980; Suh \& Trabasso, 1993; Trabasso \& Magliano, 1996; Van den Broek, Lorch, Linderholm, \& Gustafson, 2001). According to our hypothesis, explanatory inferences would be more frequent in an understanding condition than in a problem-solving condition.

Regarding association inferences, we did not have a clear hypothesis about the effect that the examined task conditions might have. Predictive inferences, as indicated above, were expected to be very few.

\section{Method}

\section{Subjects}

Thirty five second- and third-year undergraduate pre-service primary teacher students (about 21 years old) from the University of Valencia (Spain) participated in the study. These students did not have such high science standards in secondary education as the Biology students who participated in Experiment 1. However, all of them were enrolled in "Science for non-scientists", a basic general science course. The students were randomly assigned to each of the task conditions: 19 in the understanding condition and 16 in the problem-solving condition. The students were given credits.

\section{Materials}

Given that the experimental procedure did not involve written responses by the students, there was more time available for the think-aloud procedure without risking fatigue on the part of the participants. Based on this, and to obtain a sufficient number of responses, an additional passage, "Cartesian Diver”, was used in this experiment. In 
addition there was a practice passage and a cover page with instructions depending on the condition. As in Experiment 1, the students in the understanding condition were instructed to read the three target passages to understand them and be ready to take a comprehension test about their content. The test was to be administered in the following session. In the problem-solving condition the students were instructed to read the passages to solve the problems in the following session.

As in Experiment 1, the passages were the same in both conditions, except for the inclusion of a sentence requesting a calculation in the problem-solving condition.

\section{Procedure}

The students were randomly assigned to one of the two task conditions, before being individually tested in a quiet room. The think-aloud procedure followed previous applications in similar studies (Trabasso \& Magliano, 1996; Van den Broek et al., 2001). After having read the printed instructions, each individual student was verbally instructed to read the passages, saying out loud the thoughts that came to mind after reading each sentence. The student started reading the practice passage and the experimenter provided orientation when needed. After reading the practice passage, the student proceeded to the three experimental passages, counterbalanced across participants. The experimenter reminded participants of the need to verbalize their thoughts whenever they kept silent for more than five seconds after reading a sentence. All the reading and thinking aloud was digitally recorded. When all the members of the sample had finished, the participants were debriefed, informing them that there would not be a second session

\section{Measurements}

The recorded think-aloud protocols were transcribed. The inferences of central concern in this study are associations, explanations and predictions. However, subjects 
in a think-aloud task generate responses that may not be considered components of a situation model representation. For instance readers may paraphrase, reflect on their own understanding or verbalize affective reactions. Therefore we adopted the 9-item scheme of Van den Broek et al. (2001), which includes the three types of inferences that are of central concern to our work together with 6 others: paraphrase (reformulations capturing the essential meaning of the target sentence), evaluation (evaluative opinions about the text), monitor comprehension (reflections on one’s own understanding), affective response (expressions of emotional involvement), text repetition, and others (not classifiable in the previous categories). As in the Van den Broek et al. (2001) study, the main inference associated with each sentence was classified into one of these categories

\section{Results}

A total of 875 main inferences were generated on the three passages. One of the authors categorized all the inferences while another author independently categorized the first 113. The Kappa coefficient of intercoder reliability was .81, indicating very good agreement. Disagreements were resolved by discussion.

The Kolmogorov-Smirnov test was used to check for normality of distribution of associations, explanations, and predictions in the understanding condition $\left(Z_{a s s o c}=.481\right.$, $\left.p=.975 ; Z_{\text {expl }}=.942, p=.337 ; Z_{\text {pred }}=1.094 ; p=.183\right)$ and in the problem-solving condition $\left(Z_{\text {assoc }}=.538, p=.935 ; Z_{\text {expl }}=.742, p=.641 ; Z_{\text {pred }}=1.237, p=.094\right)$. Therefore, bidirectional Student's t tests were used to analyze the differences in associations and predictions, while a unidirectional t test was used for explanations, as there is a clear expectation as to the direction of the difference.

Table 2 shows average number of explanation, prediction and association inferences per student and per text. The participants generated significantly more 
explanations in the understanding condition than in the problem-solving condition $(t=$ 1.996, $p=.020)$. No significant differences between task conditions were found regarding associations $(t=.966, p=.342)$ and predictions $(t=1.806, p=.082)$. Regarding the other types of inferences included in the Van den Broek et al. (2001) scheme, there was a borderline significant difference $(t=1.963, p=.059)$ between evaluations generated in the understanding condition $\left(\mathrm{M}_{\mathrm{UND}}=4.05, \mathrm{SD}_{\mathrm{UND}}=3.44\right)$ and in the problem-solving condition $\left(\mathrm{M}_{\mathrm{PROBSOLV}}=2.25, \mathrm{SD}_{\mathrm{PROBSOLV}}=1.88\right)$. No other difference approached significance.

\section{Discussion}

The think-aloud procedure indicated that the participating students generated significantly more explanation inferences in the understanding condition than in the problem-solving condition, as expected. The differences in association inferences and prediction inferences between conditions did not reach statistical significance. Also, the understanding condition seems to have encouraged the expression of opinions about the text as shown by the borderline significant difference in evaluative opinions about the text.

The results support the assumption of different mental representations attempted under the two task conditions, thereby lending credibility to the hypothesized question generation mechanism. More explanations attempted under the understanding condition naturally result in more explanation obstacles and explanation questions in this condition compared with the problem-solving condition.

However, this new group of university students were enrolled in different studies than those participating in Experiment 1, and possible differences in scientific knowledge may have existed between the two groups. Therefore, a replication of Experiment 1 was carried out with participants taken from the same pool of teacher 
training students as those used in Experiment 2. Also, we included in this new experiment an additional measure of comprehension by asking the students to recall in writing the phenomena described in the experimental passages.

\section{Experiment 3}

\section{Method}

\section{Subjects}

Eighty second- and third-year undergraduate students (around 21 years old) from the University of Valencia were selected for this study. They were enrolled in the same course --“Science for non-scientists”-- as those participating in Experiment 2. Forty subjects were randomly assigned to each of the task conditions.

\section{Materials}

Identical to Experiment 1.

\section{Procedure}

The same as in Experiment 1, except for the request of a written recall of the phenomena presented in the passages. The students read the two passages and wrote down the questions they had on each passage. They were then asked to recall in writing the phenomena they had just read about, without being allowed to look at the passage again. According to our assumption about the mental representations built, readers’ recall protocols would include more explanations in the understanding condition than in the problem-solving condition.

\section{Measurements}

These were the same as in Experiment 1 regarding the questions asked. The Kappa coefficient of intercoder agreement for a subset of 50 questions categorized by two of the authors was 0.93 . Also, the written recall was analyzed in order to identify explanatory statements. These were selected depending on the existence of: (1) explicit 
causal markers, such as "because”, “as a consequence of”, "since”, “so that”, “therefore”"; (2) verbs explicitly stating a causal relationship, such as “cause”, “enable”, “make”, or "result in”; and (3) implicit causal relations, involving causal verbs, as in "the wind impinges on the sail's surface pushing the boat..." .

\section{Results}

Questions asked per subject and per passage are shown in Table 3. First, concerning regular passages, there was a significant difference between the association questions asked on average in the understanding condition and in the problem-solving condition ( $U=459.5, p<.001)$. Effect size in terms of Cohen's $d$ was .85. Consistent with this, there were also significant differences between questions on the unknown term in the difficult passage in the understanding condition versus the problem-solving condition ( $U=611.0, p=.036)$, and the effect size was calculated to be .50 .

Second, regarding explanation questions, the Wilcoxson matched-pairs signedranks test showed that the differences between difficulty conditions were not significant both in the understanding condition $(Z=-.06, p=.952)$ and in the problem-solving condition $(Z=-.19, p=.850)$. Therefore, the results were collapsed across conditions as in Experiment 1. The difference between task conditions is replicated here: there is a significant difference between the average number of explanation questions in the understanding condition versus the problem-solving condition $(U=181.5, p<.001)$, with a very large effect size of 1.62 .

A significant difference was found between questions asked on the discrepant event in the two task conditions: $\mathrm{M}_{\mathrm{UND}}=1.38, \mathrm{SD}_{\mathrm{UND}}=.55, \mathrm{M}_{\mathrm{PROBSOLV}}=.77$, $\mathrm{SD}_{\mathrm{PROBSOLV}}=.85(U=385.5, p<.001)$. Also, regarding the written recall, analysis of the explanations showed a significant difference between task conditions: .60 
explanation statements per subject in the understanding condition versus .34 in the problem-solving condition $(U=530.0, p=.005)$.

Third, the difference in prediction questions between the understanding condition and the problem-solving condition did not reach statistical significance ( $U=$ $679.0, p=.078)$.

Subjects in this experiment asked significantly more questions than subjects in Experiment 1: a grand average of 2.00 questions per subject and per passage versus 1.12 in Experiment $1(U=1914.0, p=.002)$. When analyzed according to condition, the difference was found to be significant in the understanding condition ( $U=261.0, p<$ $.001)$ but not in the problem-solving condition $(U=646.0, p=.705)$.

\section{Discussion}

The results in Experiment 3 replicate the main finding in Experiment 1. Again, there were significantly more explanation questions asked in the understanding condition than in the problem-solving condition. However the difference between conditions is significant not only for explanation questions but also for association questions in this experiment. The experiment indicates that the understanding goal led to the identification of more explanation obstacles and association obstacles, and therefore to more questions of these types, than the problem-solving goal. But readers are especially sensitive to explanation obstacles when reading for understanding this kind of texts: the difference between conditions is much greater, in terms of effect size, for explanation questions than for association questions. Prediction questions, as expected from previous research, were too few to show potential differences due to our manipulations.

The recall measure provided support to the differences in mental representations directly examined in Experiment 2: the students in the understanding condition of this 
experiment included significantly more explanation statements than in the problemsolving condition. Again, a greater concern for explanations is associated with an understanding goal than with a (algorithmic) problem-solving goal.

The larger number of questions asked by students in the understanding condition in this experiment should also be considered. Several confounds may account for this difference. First, although the passages were built so that they would not involve difficult scientific content, relevant knowledge was probably different for the student samples in Experiments 1 and 3. The students in Experiment 1 were enrolled in more detailed and elaborate science courses than the participants in Experiment 3. The latter may have encountered more obstacles to understanding the passage and this, in turn, would have led to more questions asked, of both the association type and the explanation type. However, solving the problem was easy enough not to pose special difficulties to any of the two samples. A second possible influence on the total number of questions asked in the understanding condition is related to contextual variables. The academic setting in Experiment 3 was different from that in Experiment 1 in that the understanding task may have been more precisely defined in the former. Students in Experiment 1 knew relatively well the kind of comprehension test they would be taking, since they had previous testing experience. However, this was not the case in Experiment 3, where the students would only have had a general knowledge of the kind of questions that they would be required to answer in the next session. Also, the task was more naturally integrated into the course activities in Experiment 1 than in Experiment 3. Physics students in Experiment 1 may have considered the questioning activity as a tool to suitably perform what they considered to be the academic task: answering the understanding test or, in the alternative condition, solving the problem. Teacher training students in Experiment 3, being more familiar with educational 
problems, may not have considered the questioning task as instrumental toward a central performance goal, as students in Experiment 1 did, but rather as an interesting task in itself. In other words, the students' goal orientation in Experiment 1 may have been closer to a performance condition, as compared to a mastery condition in Experiment 2 (Ames, 1992; Dweck, 1986).

In summary, this experiment replicates the central findings of Experiment 1. However, the results pose new question marks on various factors that influence questioning in classroom contexts, such as the effect of subject matter knowledge or of the students' goal orientation in the reading task.

\section{General Discussion}

In this study we have attempted to show that reading obstacles and the resulting questioning by students should not be considered absolute, but rather relative, according to the reading goals involved. Two specific results show the dependence of questioning on reading goals

First, we found a robust significant effect of the task on explanation questions. Students ask significantly more explanation questions in the understanding condition than in the problem-solving condition, with large effect sizes in the two experiments. A significant difference is also found for explanation questions specifically relating to the discrepant event.

Second, task condition was found to have a different influence on association questions and explanation questions posed by the students. Although the direction of the difference in association questions between the task conditions was the same in both experiments, the difference only reached statistical significance in the second questioning experiment. In contrast, there was a strong effect of task condition for explanation questions in the two experiments, as shown by the effect size. This effect 
could be interpreted as showing that, for the understanding and problem-solving tasks at least, representing entities seems to be a more stable requirement for the students than explaining them. This interpretation is in agreement with Graesser, Langston, \& Baggett's (1993) proposal of a canonical ordering of question-asking during knowledge exploration: questions on definitional information about entities precede causal, explanation questions.

There were too few prediction questions to examine differences based on our manipulations. Although prediction is considered to be an important skill, particularly in scientific thinking (Lavoie, 1993, 1999), students reading scientific texts in situations such as those in our experiments find very few prediction obstacles. Our tentative explanation for this finding is based on the small number of predictive inferences made on these types of texts (Millis \& Graesser, 1994). However, the lack of prediction obstacles in a situation where students were explicitly asked to consider reading difficulties, and ask about them, points to a significant problem for future research: what text, task, or context variables would enhance the asking of prediction questions?

The hypothesized differences in question asking were based on a mechanism that involved discourse representations as key elements in question generation. Our second experiment supported the assumption of different discourse representations built under the two question triggering conditions. Differences in mental representations of discourse depending on reading goal had already been demonstrated by previous research discussed above. But our study specifically substantiated the existence of differences in the explanation inferences that are generated under an understanding condition or a problem-solving condition.

In conclusion, the present study has shown that obstacles and the resulting questions, given a particular text and a particular reader, should be more appropriately 
regarded as variable and relative to a reader's goal. An educationally relevant consequence follows from this. Questions frequently observed in school situations are not aimed at solving important comprehension problems, but are shallow or focused on scarcely important procedural information such as "How many pages do I have to read?” (Commeyras, 1995; Good, Slavings, Harel, \& Emerson, 1987; Dillon, 1988; Scardamalia \& Bereiter, 1992). This poor questioning behavior may be a natural consequence of the poor processing goals and associated mental representations attempted by students.

\section{References}

Ames, C. (1992). Classrooms: Goals, structures, and student motivation. Journal of Educational Psychology, 84(3), 261-271.

Baruk, S. (1985). L'age du capitaine. Paris: Seuil.

Coleman, E. B., Brown, A. L., \& Rivkin, I. D. (1997). The effect of instructional explanations on learning from scientific texts. The Journal of the Learning Sciences, 6, 347-365.

Collins, A., Brown. J. S., \& Larkin, K. M. (1980). Inference in text understanding. In R. J. Spiro, B. C. Bruce, \& W. F. Brewer (Eds.), Theoretical issues in reading comprehension (pp. 385-407). Hillsdale, NJ: Lawrence Erlbaum Associates.

Commeyras, M. (1995). What can we learn from students’ questions? Theory into Practice, 34(2), 101-106.

Costa, J., Caldeira, M. H., Gallástegui, \& Otero, J. (2000). An analysis of question asking on scientific texts explaining natural phenomena. Journal of Research in Science Teaching, 37, 602-614.

Coté, N., Goldman, S., \& Saul, E. U. (1998). Students making sense of informational text: Relations between processing and representation. Discourse Processes, 25, 1-53. 
Dillon, J. T. (1988). Questioning and teaching: a manual of practice. London: Croom Helm.

Dillon, J. T. (1990). The practice of questioning. London: Routledge.

Dweck, C. S. (1986). Motivational processes affecting learning. American Psychologist, 41(10), 1040-1048.

Engelhardt, P. V., \& Beichner, R. J. (2004). Students' understanding of direct current resistive electrical circuits. American Journal of Physics, 72(1), 98-115.

Gaveleck, J. R., \& Raphael, T. E. (1985). Metacognition, instruction and the role of questioning activities. In D. L. Forrest-Pressley, G. E. Mac Kinnon, \& T. G. Waller (Eds.), Metacognition, cognition and human performance (pp. 103-136). Orlando: Academic Press.

Geiger, J. F., \& Millis, K. K. (2004). Assessing the impact of reading goals and text structures on comprehension. Reading Psychology, 25, 93-110.

Glenberg, A. M., Kruley, \& P., Langston, W. E. (1994). Analogical processes in comprehension: simulation of a mental model. In M. A. Gernsbacher (Ed.), Handbook of psycholinguistics (pp. 609-640). San Diego, CA: Academic Press.

Good, T. L., Slavings, R. L., Harel, K. H., \& Emerson, H. (1987). Student passivity: a study of question asking in K-12 classrooms. Sociology of Education, 60, 181199.

Graesser, A.C., Baggett, W., \& Williams, K. (1996). Question-driven explanatory reasoning. Applied Cognitive Psychology, 10, S17-S32.

Graesser, A. C., \& Kreuz, R. J. (1993). A theory of inference generation during text comprehension. Discourse Processes, 16, 145-160.

Graesser, A. C., Langston, M. C., \& Baggett, W. B. (1993). Exploring information about concepts by asking questions. In G. V. Nakamura, R. M. Taraban, \& D. Medin 
(Eds.), The psychology of learning and motivation: vol 29, Categorization by humans and machines (pp. 411-436). Orlando, Fl: Academic Press.

Graesser, A.C., Lu, S., Olde, B.A., Cooper-Pye, E., \& Whitten, S. (2005). Question asking and eye tracking during cognitive disequilibrium: Comprehending illustrated texts on devices when the devices break down. Memory and Cognition, 33, 1235-1247.

Graesser, A. C., \& McMahen, C. L. (1993). Anomalous information triggers questions when adults solve problems and comprehend stories. Journal of Educational Psychology, 85, 136-151.

Graesser, A. C., Millis, K. K., \& Zwaan, R. A. (1997). Discourse comprehension. Annual Review of Psychology, 48, 163-189.

Graesser, A. C., \& Person, N. K. (1994). Question asking during tutoring. American Educational Research Journal, 31, 104-137.

Graesser, A. C., Person, N. K., \& Huber, J. D. (1992). Mechanisms that generate questions. In T. Lauer, E. Peacock, \& A. C. Graesser (Eds.), Questions and information systems (pp. 167-187). Hillsdale, NJ: Erlbaum.

Graeser, A, C., Singer, M., \& Trabasso, T. (1994). Constructing inferences during narrative text comprehension. Psychological Review, 3, 371-395.

Graesser, A. C., \& Zwaan, R. A. (1995). Inference generation and the construction of situation models. In C. A. Weaver, S. Mannes, \& C. R. Fletcher (Eds.), Discourse comprehension: Strategies and processing revisited. Essays in honor of Walter Kintsch (pp. 117-139). Hillsdale, NJ: Erlbaum.

Hestenes D., Wells M., \& Swackhamer G. (1992). Force concept inventory. The Physics Teacher, 30, 141-158. 
Hung, W., \& Jonassen, D. H. (2006). Conceptual understanding of causal reasoning in physics. International Journal of Science Education, 28, 1601-1621.

Ishiwa, K., Macías, A., Maturano, C., Otero, J. (2012). Questioning on science texts: A taxonomy of its causes. Manuscript submitted for publication.

Johnson-Laird, P. (1983). Mental models. Towards a cognitive science of language, inference, and consciousness . Cambridge: Harvard University Press.

Kane, J. W., \& Sternheim, M. M. (1992). Física. (J. Casas and D. Jou, Trans). Barcelona: Reverté (Original work published in1980).

Keenan, J. M., Baillet, S. D., \& Brown, P. (1984). The effects of causal cohesion on comprehension and memory. Journal of Verbal Learning and Verbal Behavior, 23, $115-126$.

King, A. (1989). Effects of self-questioning training on college students’ comprehension of lectures. Contemporary Educational Psychology, 14, 1-16.

Kintsch, W. (1988). The role of knowledge in discourse comprehension: A constructionintegration model. Psychological Review, 95, 163-182.

Kintsch, W. (1998). The representation of knowledge in minds and machines. International Journal of Psychology, 33, 411-420.

Kintsch, W., Welsch, D. M., Schmalhofer, F., \& Zimny, S. (1990). Sentence memory: A theoretical analysis. Journal of Memory and Language, 29, 133-159.

Klin, C. M. (1995). Causal inferences in reading: From immediate activation to long-term memory. Journal of Experimental Psychology: Learning, Memory and Cognition, 21, 1483-1494.

Lavoie, D. (1993). The development, theory, and application of a cognitive-network model prediction problem solving in biology. Journal of Research in Science Teaching, 14(2), 169-175. 
Lavoie, D. (1999). Effects of emphasizing hypothetico-predictive reasoning within the science learning cycle on high school students’ process skills and conceptual understanding in biology. Journal of Research in Science Teaching, 36, 11271147.

León, J. A., \& Pérez, O. (2003). Taxonomías y tipos de inferencias. In J.A. León (Ed.), Conocimiento y discurso. Claves para inferir y comprender (pp. 45-65). Madrid: Pirámide.

Lorch, R. F., Lorch, E. P., \& Klusewitz, M. A. (1993). College students' conditional knowledge about reading. Journal of Educational Psychology, 85, 239-252.

Mills, C. B., Diehl, V. A., Birkmire, D. P., \& Mou, L. (1995). Reading procedural texts: Effects of purpose for reading and predictions of reading comprehension models. Discourse Processes, 20, 79-107.

Millis, K., \& Graesser, A. (1994). The time-course of constructing knowledge-based inferences for scientific texts. Journal of Memory and Language, 33, 583-599.

Narvaez, D., Van den Broek, P., \& Barrón-Ruiz, A. B. (1999). The influence of reading purpose on inference generation and comprehension in reading. Journal of Educational Psychology, 91, 488-496.

Newell, A., \& Simon, H.A. (1972). Human problem solving. Englewood Cliffs, NJ: Prentice Hall.

Otero, J. (2002). Noticing and fixing difficulties in understanding science texts. In J. Otero, J.A. León, A. Graesser (Eds.). The Psychology of Science Text Comprehension (pp. 281-307). Mahwah, N.J.: Lawrence Erlbaum Associates

Otero, J. (2009). Question generation and anomaly detection in texts. In D. Hacker, J. Dunlosky, \& A. Graesser (Eds.), Handbook of Metacognition in Education (pp. 47-59). New York: Routledge. 
Otero, J., \& Graesser, A. (2001). PREG: Elements of a model of question asking. Cognition and Instruction, 19, 143-175.

Oakhill, J. (1993). Children’s difficulties in reading comprehension. Educational Psychology Review, 5(3), 223-237.

Person, N. K., Graesser, A. C., Magliano, J. P., \& Kreuz, R. J. (1994). Inferring what the student knows in one-to-one tutoring: The role of student questions and answers. Learning and Individual Differences, 6, 205-29.

Scardamalia, M., \& Bereiter, C. (1992). Test-based and knowledge-based questioning by children. Cognition and Instruction, 9, 177-199.

Schmalhofer, F., \& Glavanov, D. (1986). Three components of understanding a programmer’s manual: Verbatim, propositional, and situational representations. Journal of Memory and Language, 25, 279-294.

Singer, M., \& Gagnon, N. (1999). Detecting causal inconsistencies in scientific text. In S. R. Golman, A. Graesser, \& P. van den Broek (Eds.), Narrative comprehension, causality, and coherence: Essays in honor of Tom Trabasso (pp. 179-194). Mahwah, N.J.: Lawrence Erlbaum Associates.

Suh, S. Y., \& Trabasso, T. (1993). Inferences during reading: Converging evidence from discourse analysis, think-aloud protocols and recognition priming. Journal of Memory and Language, 32, 279-300.

Trabasso, T., \& Magliano, J. P. (1996). Conscious understanding during comprehension. Discourse Processes, 21, 255-287.

Trabasso, T., \& Sperry, L. L. (1985). The causal basis for deciding importance of story events. Journal of Memory and Language, 24, 595-611. 
Trabasso, T., \& Suh, S. (1993). Understanding text: Achieving explanatory coherence through on-line inferences and mental operations in working memory. Discourse Processes, 12, 1-25.

Van den Broek, P. (1990). Causal inferences and the comprehension of narrative texts. In A. C. Graesser and G. H. Bower (Eds.), Inferences and text comprehension. San Diego: Academic Press.

Van den Broek, P., Lorch, R. F., Linderholm T., \& Gustafson M. (2001). The effects of readers' goals on inference generation and memory for texts. Memory \& Cognition, 29, 1081-1087.

Van der Meij, H. (1988). Constraints on question asking in classrooms. Journal of Educational Psychology, 80, 401-405.

Van Dijk, T., \& Kintsch, W. (1983). Strategies of discourse comprehension. New York: Academic Press.

VanLehn, K. (1989). Problem solving and cognitive skill acquisition. In M. I. Posner (Ed.), Foundations of cognitive science (pp. 527-579). Cambridge, Massachusetts: The MIT Press.

Varnhagen, C. K. (1991). Text relations and recall for expository prose. Discourse Processes, 14, 399-422.

Weaver, C.A. (1990). Constraining factors in calibration of comprehension. Journal of Experimental Psychology: Learning, Memory, \& Cognition, 16, 214-222.

Wiley, J., \& Myers, J. L. (2003). Availability and accessibility of information and causal inferences from scientific text. Discourse Processes, 36, 109-129.

Wong, B. Y. L. (1985). Self-questioning instructional research: A review. Review of Educational Research, 55, 227-268. 


\section{Appendix}

\section{Example of Passage Used in the Questioning Experiments}

Read carefully the description of the following phenomenon, trying to understand it.

\section{Sailing}

Sail (Afelial) boats are used since ancient times. The wind impinges on the surface of sails (afelials), which push the boat across the water. However, sail (afelial) boats have been able to navigate against the wind since several centuries ago. When they navigate against the wind, sail (afelial) boats are able to reach speeds up to twice the square root of the wind's speed at that moment. A suitable wind for sailing may have a speed of $30 \mathrm{~km} / \mathrm{h}$.

- State any queries or questions that you may have so that you may correctly answer the questions in the comprehension test the next day. [Understanding version]

- Calculate the speed of the boat in this case.

State any queries or questions that you may have so that you may correctly solve the problem the next day. [Problem-solving version] 
Footnotes

${ }^{1}$ The Spanish equivalents were used. 
Table 1

Questions per Subject and per Passage, in the different conditions (Standard Deviations in brackets). The numbers corresponding to the association questions in the difficult passage refer to the sum of questions about the unknown term plus the rest of the association questions.

\begin{tabular}{ccccc}
\hline \multirow{2}{*}{$\begin{array}{c}\text { Question } \\
\text { Type }\end{array}$} & \multicolumn{2}{c}{ Regular Passage } & \multicolumn{2}{c}{ Difficult Passage } \\
\cline { 2 - 5 } & Understanding & Problem Solving & Understanding & Problem Solving \\
\hline Association & $.76(1.10)$ & $.68(.81)$ & $1.06(1.07)$ & $.94(.95)$ \\
\hline Explanation & $.76(.89)$ & $.24(.61)$ & $.82(.87)$ & $.12(.33)$ \\
\hline Prediction & $.09(.38)$ & $.06(.24)$ & $.09(.38)$ & $.09(.29)$ \\
\hline
\end{tabular}


Table 2

Average number of explanation, prediction and association inferences per student and per passage (standard deviations in brackets)

\begin{tabular}{lcc}
\cline { 2 - 3 } \multicolumn{1}{c}{ Inference Type } & Understanding & Problem-solving \\
\hline Association & $2.00(1.36)$ & $1.50(.71)$ \\
\hline Explanation & $1.18(1.03)$ & $.64(.65)$ \\
\hline Prediction & $.37(.49)$ & $.27(.41)$ \\
\hline
\end{tabular}


Table 3

Questions per Subject and per Passage, in the different conditions (Standard Deviations in brackets). The numbers corresponding to the association questions in the difficult passage refer to the sum of questions about the unknown term plus the rest of the association questions.

\begin{tabular}{ccccc}
\hline \multirow{2}{*}{$\begin{array}{c}\text { Question } \\
\text { Type }\end{array}$} & \multicolumn{2}{c}{ Regular Passage } & \multicolumn{2}{c}{ Difficult Passage } \\
\cline { 2 - 5 } & Understanding & Problem Solving & Understanding & Problem Solving \\
\hline Association & $1.25(1.26)$ & $.37(.70)$ & $1.98(1.90)$ & $1.13(1.11)$ \\
\hline Explanation & $1.90(1.24)$ & $.45(.71)$ & $1.85(1.31)$ & $.43(.68)$ \\
\hline Prediction & $.23(.48)$ & $.07(.35)$ & $.20(.69)$ & $.07(.27)$ \\
\hline
\end{tabular}

